\title{
Global Population Aging, National Development Level, and Vulnerability to the Pandemic
}

This article was published in the following Dove Press journal:

Risk Management and Healthcare Policy

\author{
Bocong Yuan (iD) \\ Jiannan $\mathrm{Li} \mathbb{D}^{2}$ \\ Hairong Zhao' \\ Guojun Zeng (D) \\ 'School of Tourism Management, Sun Yat- \\ Sen University, Guangzhou, People's \\ Republic of China; ${ }^{2}$ Institute of Advanced \\ Studies in Humanities and Social Sciences, \\ Beijing Normal University, Beijing, \\ People's Republic of China
}

Purpose: This study examined the roles of population aging and national development level in affecting different phases of novel coronavirus disease development with a view to advancing preparedness and corresponding policy.

Methods: Regression analysis was conducted using multisource data from the World Bank and Johns Hopkins COVID-19 Dashboard.

Results: Population aging is positively associated with confirmed cases of day-10, day-20, and day-30. The positive association between population aging and death does not emerge until day-20. Countries with a higher proportion of older males face higher risks of death.. Countries with a higher proportion of males aged 70-74 years are at the highest risk of confirmed cases. National development level is not associated with confirmed cases, but developing countries face significantly higher risks of death of day-10 and day-20.

Conclusion: Prevention and control policies for older adults and underdeveloped areas and sex differences need to be studied.

Keywords: population aging, sex difference, policy preparedness, national development level, pandemic

\section{Introduction}

The aged population is more susceptible to novel coronavirus disease, due to more severe underlying physical and mental health problems. ${ }^{1}$ Half the admissions to hospitals, over half the admissions to intensive care units, and $80 \%$ of deaths related to novel coronavirus disease are people $>65$ years old in China and the US. ${ }^{2}$ The case-mortality rate of those aged $>80$ years and those with comorbidities are higher $(14.9 \%-20.2 \%$ in different countries $){ }^{3,4}$ and nursinghome residents face the higher risks $\left(49 \%-62 \%\right.$ mortality rate). ${ }^{4,5}$ The age gradient in mortality is observed among older adults with novel coronavirus disease. Specifically, rates of severe symptoms are different among those aged $>80,65-79$, and $50-64$ years $\left(81.3 \%, 43.2 \%\right.$, and $19.8 \%$, respectively) ${ }^{6}$ and the mortality rate is disproportionately higher for the older groups $(18.8 \%, 4.5 \%$, $1.2 \%$, respectively). ${ }^{4,6}$ Among patients with novel coronavirus disease, older patients have a higher mortality rate, due to the high case-fatality rate and symptomatic infection rate. ${ }^{7}$ This fact could be influenced by both the physiological aging process and especially the greater prevalence in older adult patients of frailty and comorbidities, ${ }^{8,9}$ where chronic obstructive pulmonary disease, diabetes, hypertension, cardiovascular disease, and malignancy can reduce intrinsic capacity and resilience and hinder the fight against infections. ${ }^{9}$
Correspondence: Jiannan Li

Beijing Normal University, 19

Xinjiekouwai Street, Haidian District,

Beijing, People's Republic of China

Email9I I22020 I I I@bnu.edu.cn

Guojun Zeng

Sun Yat-Sen University, I 35 West Xingang

Road, Haizhu District, Guangzhou,

People's Republic of China

Email zenggj@mail.sysu.edu.cn 
Although countries with deep population aging are mainly developed countries that have advanced health systems, the sudden surge in medical demand within a short period still overburdens the health system and can render it close to collapse. ${ }^{10}$ Developing areas whose health systems are more vulnerable and bearing the brunt of the rush for medical resources can be even worse hit. In many Latin American countries, universal health-care coverage is far from being reached. ${ }^{11}$ Self-medication, which can bring great health risks, is still prevalent, ${ }^{12}$ and targeted health policy and planning toward lower- and middle-class residents is insufficient in underdeveloped areas. ${ }^{13,14}$ In some less developed areas like Africa, the situation can be severe, as the health system is worse prepared for pandemics and the average age is becoming older than before. ${ }^{15,16}$ In west Africa, there are fewer than five hospital beds and two doctors per 10,000 population, US $\$ 50$ health expenditure per capita. In comparison, in Italy, one of the epicenters, there are 34 hospital beds and 41 doctors per 10,000 population, with $\$ 2840$ health expenditure per capita. ${ }^{17}$ Meanwhile, it is reported that Africa has become a young but rapidly aging continent, with a fourfold increase in the absolute number of old adults (between 2010-2050, from 56 to 215 million) which is close to the number in Europe (241 million). ${ }^{18}$ The composite risk of lower national development level and a rapidly aging population structure can leave developing areas at a disadvantage when faced with the pandemic.

A deep examination of associations among population aging, national development level, and the development of novel coronavirus disease is much needed. Though there has been some research alerting policymakers to the risk status of older adults, less attention has been paid to country-level relationships among population aging, national development level, and risk of novel coronavirus disease. This study divided the structure of population aging to reveal the disparity in vulnerability to novel coronavirus disease between countries with varying proportions of older adults. Also, sex differences can be seen in the manifestation and pathophysiology of many diseases, ${ }^{8}$ and sex-stratified analysis was done to further divide the structure of population aging, and thus to reveal differences in sex structure vulnerable to novel coronavirus disease among countries with varying proportions of older adults. Moreover, this study classifies national development levels to discuss the disparity in vulnerability to novel coronavirus disease between developed and developing countries. These devoted efforts could enrich relevant literature and provide policy recommendations based on findings.

\section{Literature Review Population Aging and the Risk of Infectious Disease}

Older adults usually suffer from a series of comorbidities, such as chronic obstructive pulmonary disease, diabetes, hypertension, and cardiovascular disease, which significantly predict the severity of novel coronavirus disease and make them most susceptible to it. ${ }^{19}$ Those aged $\geq 65$ years old account for $45 \%$ of hospitalizations, $53 \%$ of intensive care-unit admissions, and $80 \%$ of fatalities as of late March $2020 .{ }^{20}$ In a survey of nursing homes in the UK, $26 \%$ of nursing-home residents passed away within the initial 2 months of the outbreak, with all-cause mortality increasing by $203 \%$ compared to years prior, among which $40 \%$ had tested positive and of these, $43 \%$ had been found to be asymptomatic. ${ }^{21}$ Nursing homes of higher quality and on a larger scale have surprisingly experienced severer situations. ${ }^{22}$ In a survey covering 9,395 nursing homes in the US, $13.1 \%$ of small ( $<50$ beds), $29.1 \%$ of medium-sized ( $50-150$ beds), and $51.7 \%$ of large ( $>150$ beds) establishments had reported confirmed cases. ${ }^{22}$

Macroscopically, although regions with deep population aging have well-structured health-care systems and longer life expectancy, they may also face a high number of confirmed cases and high mortality from novel coronavirus disease, contributed to by population aging, since an upsurge in medical demand overburdens current health systems. ${ }^{23}$ Most health systems around the world lack resilience to cope well with the sharp growth in medical demands of specific diseases, leading many general health-care services messed up and to give way to this priority. ${ }^{24}$ As such, a run on finite medical resources weakens advantages of health systems in developed countries. The disparity in mortality from epidemics can thus be driven more by differences in demographic structure than by the capacity of health systems in the short term. ${ }^{25}$ Some countries with a younger population structure, like India, seem to have outperformed the US and some of European nations in mortality rates during epidemics. ${ }^{26}$ Even within a single country, the disparity in vulnerability to a pandemic can stem from population aging at different paces. The higher mortality from a pandemic is found in places that face social challenges resulting from deeper population aging, such as a mismatch 
between medical resources and the need for long-term care or the higher ratio of residents in weak physical condition. ${ }^{27}$

\section{Sex Differences and Risk Disparity in the Pandemic}

Sex differences in clinical severity and mortality during the novel coronavirus disease crisis have been observed, where males are generally at higher risk than females in terms of case fatality and other severe outcomes. ${ }^{28,29}$ This might partially result from differences between males and females in hygiene knowledge and awareness, adherence to protective guidelines, and health-behavior practices. It has been reported that females have exhibited a higher level of intention to conform with epidemic-prevention guidelines on hand hygiene, health behavior, and individual protection. ${ }^{30}$ They have been found to have higher daily frequency of hand-washing and using alcohol-based sanitizer than males. ${ }^{30}$ A higher proportion of females report adequate hand-washing before leaving restrooms,31,32 whereas males have more reasons for not washing their hands (eg, no time, inconvenience, no need, do not feel like doing this) than females (eg, skin problems). ${ }^{30}$ Females also demonstrate more sneezing/coughing into their elbows, ${ }^{33}$ more conscious avoidance of unnecessary contact with people while ill, and more adherence to wearing a face mask in this pandemic. ${ }^{30}$ Moreover, sex difference in health-behavior practices may also result in the risk disparity in the novel coronavirus disease pandemic. The severity of symptoms of this pandemic is associated with a series of comorbidities, such as hypertension, diabetes, cardiovascular disease, and chronic obstructive pulmonary disease, which are commonly found in heavy smokers. ${ }^{34}$ The sex disparity in tobacco use is viewed as an old enemy in a new guise in the context of the pandemic. ${ }^{35}$ For example, the odds of tobacco use among males are more than twice those of females in Mumbai, India. ${ }^{36}$ The sex disparity in initiation, maintenance, and outcome expectancy of tobacco use is not limited to cigarettes, but can also be seen in vaping, ecigarettes, smokeless tobacco, and chewing tobacco. ${ }^{37,38}$

\section{National Development Level and Potential Risk in This Crisis: The Pros and Cons}

The potential influence of national development level on the risk of novel coronavirus disease can manifest in two ways and may thus be unclear. The bright side lies in that the higher national development level is often associated with better health services, considered the key for a country to reduce the mortality rate from novel coronavirus disease. Less developed areas may face greater challenges, due to a lack of necessary medical devices, such as ventilators and personal protective equipment. ${ }^{39,40}$ The long-standing social vulnerability and worse coverage of their health systems can impose great risk on underdeveloped areas when faced with public-health crises. ${ }^{41,42}$ Also, comparatively worse public administration and policy response and lower education and economic levels in less developed areas may also contribute to higher risks of mortality in this pandemic. ${ }^{43}$ As noted earlier, smoking-related comorbidities (eg, hypertension, diabetes, cardiovascular disease, and chronic obstructive pulmonary disease) are closely associated with the severity of symptoms of this disease. ${ }^{34}$ Studies have demonstrated higher prevalence of tobacco use in areas with great social vulnerability, where populations face poverty, and the less educated and illiterate account for a large percentage. ${ }^{44,45}$ Therefore, in the initial phase of the pandemic, where the run on medical resources is yet to happen, developed areas may have the advantage of completer health systems and better economic support.

However, many developing areas seem to have outperformed developed areas in lowering the mortality rate, although the latter have better health-care facilities, higher-quality drinking water and sanitation, and longer life expectancy. ${ }^{46,47}$ Some studies have proposed that the lower level of urbanization associated with decentralized population distribution in developing areas can retard the spread of the pandemic. ${ }^{48}$ Long-term care facilities in developing areas are far from sufficient, and their accessibility depends on highly variable rural-urban divides and managerial standard of care. ${ }^{49}$ Such a shortage, however, surprisingly turns out to be an advantage in the pandemic. In many developed countries, nursing homes and longterm care facilities have been found to be closely related to cluster infection. ${ }^{50}$ In this case, the higher level of urbanization and better access to care services for the aged may turn into an extra burden for developed countries when measures of epidemic prevention and control are insufficient.

\section{Methods}

The percentage of the population aged $>65$ years for 2018 published by the World Bank is the most recent data available to measure the aging population at a national level (http:// datatopics.worldbank.org/universal-health-coverage/corona virus). Since the date of emergence of initial novel 
coronavirus disease cases varies across countries and initial emergence may not have reached a serious stage, we set the first day of reaching ten cases as day-1 for each country. Data of confirmed cases and deaths from novel coronavirus disease (January 21 to April 27, 2020) came from the Johns Hopkins COVID-19 Dashboard (https://coronavirus.jhu.edu/ map.html). day-10, day-20, and day-30 confirmed cases and deaths that reflect different phases of the pandemic's development, are examined as outcome variables. ${ }^{51}$ National development level is classified by the World Bank into high-income, upper-middle-income, lower-middle-income, and low-income countries. Regression analysis was conducted using Stata 16.0:

Confirmed cases and deaths (day-10, day-20, and day-30) $=\beta_{0}+\beta_{1}$ population aging $+\beta_{2}$ national development level $+\varepsilon$

\section{Results}

Figure 1A depicts the world distribution of population aging. It is shown that population aging is occurring in many of the world's biggest economies, and is much severer in developed countries than developing ones. Europe and Japan are just about the reddest regions on the map, with the highest percentages of aging populations in the world. These distribution characteristics are also seen in the case of both older female (Figure 1B and D) and older male populations (Figure 1C and $\mathrm{E})$.

Figure 2 provides a depiction of the spatial distribution of confirmed cases and deaths around the world. It is shown that confirmed cases and deaths from day-10 to day-30 are deteriorating in most countries. Figure 3 illustrates the phase dynamics of distribution of confirmed cases and deaths. The histograms of confirmed cases and deaths gradually move rightward with time, showing that the pandemic has not been well controlled and substantial increases in confirmed cases and deaths have documented by more countries at day-30 than day-10. Flowcharts of regression samples are more clearly shown in Figure 4.

Table 1 (panels A-C) presents the main results. Population aging positively predicts day-10, day-20, and day-30 confirmed cases $(p<0.01)$. However, population aging affects only day-20 and day-30 deaths $(p<0.01)$ and does not significantly affect day-10 deaths ( $p>0.05)$. These results indicate that the effect of population aging on confirmed cases emerges immediately, but displays a delay in terms of deaths.

National development level is not associated with day-10, day-20, or day-30 confirmed cases ( $p>0.05)$, or with day-30 deaths $(p>0.05)$, whereas it is significantly related to day-10 and day-20 deaths $(p<0.05)$. These findings indicate that day-
10, day-20, and day-30 confirmed cases do not vary with national development level. There is little disparity in day-30 deaths among countries at different development levels, although additional day-10 and day-20 deaths are significantly identified as national development level declines. These data may reflect that this health crisis can be coped with initially by countries at higher development levels; however, with the increasing severity of this crisis over time, it seems difficult for countries at higher development levels to cope much better than others.

Table 1 (panel D) divides the structure of aging populations grouped by age and sex. For confirmed cases, it is shown that countries that have a higher proportion of males aged 70-74 years are at highest risk (with the largest magnitude of coefficients) compared with other cases (ie, a higher proportion of males aged $>80$ years, of females aged 70-74 years, or of females aged $>80$ years).

For deaths, it is indicated that countries that have a higher proportion of males aged 70-74 years and $>80$ years are at higher risk than those with a higher proportion of females of the same ages.

\section{Discussion}

Since there is greater prevalence of frailty and comorbidities among older adults, 8,9 countries with older population structures are faced with greater pressure in the novel coronavirus disease crisis. Such pressure is manifested more as confirmed cases rather than deaths, and the influence of population aging on deaths shows a delay. The findings of little disparity between developed and developing countries in confirmed cases and longer-term deaths (day-30 deaths) imply that even for developed countries, the epidemic outbreak was a big shock and overburdened their health systems. In northern Italy, for example, the number of people with novel coronavirus disease far exceeds available medical resources (eg, ventilators, intensive care-unit beds, and hospital beds). ${ }^{52}$ For short-term deaths (eg, day-10 and day-20 deaths), developing countries show significant additional mortality risks. Besides inadequate health systems in developing countries, this finding may also point to greater prevalence of tobacco use in developing countries, where the poor, less educated, and illiterate account for a higher population proportion, ${ }^{44,45}$ as smoking-related comorbidities have been found to be closely associated with the severity of symptoms of this pandemic. ${ }^{39}$ Further, when taking sex difference and age subgroups into consideration, countries with a higher proportion of older males face higher risks, among which those with a higher proportion of males aged 70-74 years are at highest risk. Similarly, higher smoking 


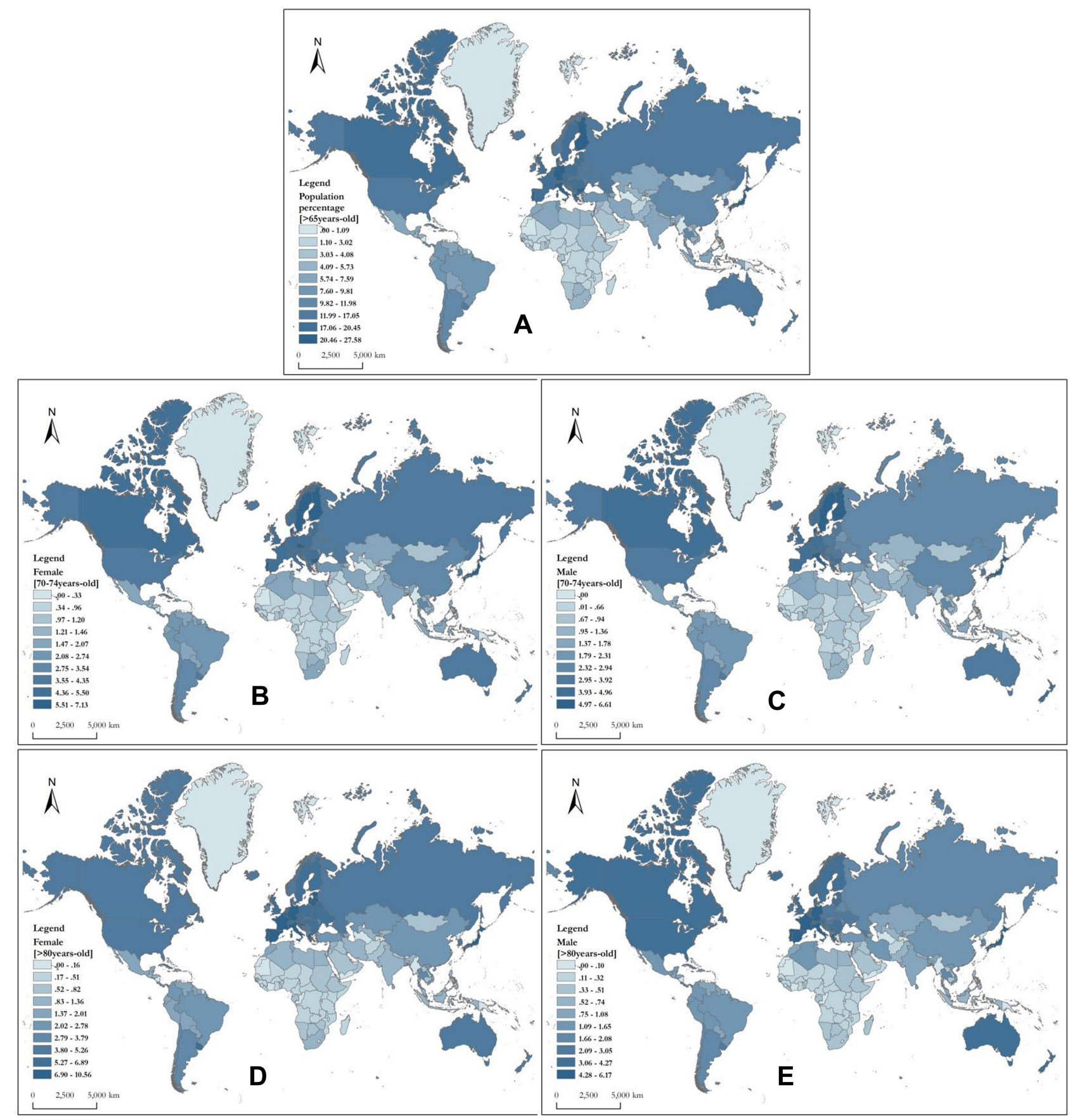

Figure I Population aging around the world: percentages of those aged $>65$ years (A), females aged 70-74 years (B), males aged 70-74 years (C), females aged >80 (D), and males aged $>80$ years $(\mathbf{E})$.

prevalence among males than females may be a contributing factor to this finding. ${ }^{53}$

\section{Policy Implications}

Elevated Prevention and Control Measures Are Needed for Places Where Old Adults Gather

As the influence of population aging on confirmed cases of novel coronavirus disease is significant in both the short and long term, irrespective of national development levels, elevated prevention and control measures that focus on gathering places of old adults (especially nursing homes, as the dominant collective residence of older adults) should be emphasized in both developed and developing countries. A lack of regularly scheduled training and updates in infection control is a critical problem resulting in insufficient prevention and control over infection in nursing homes. ${ }^{54}$ Full training (including taking a 

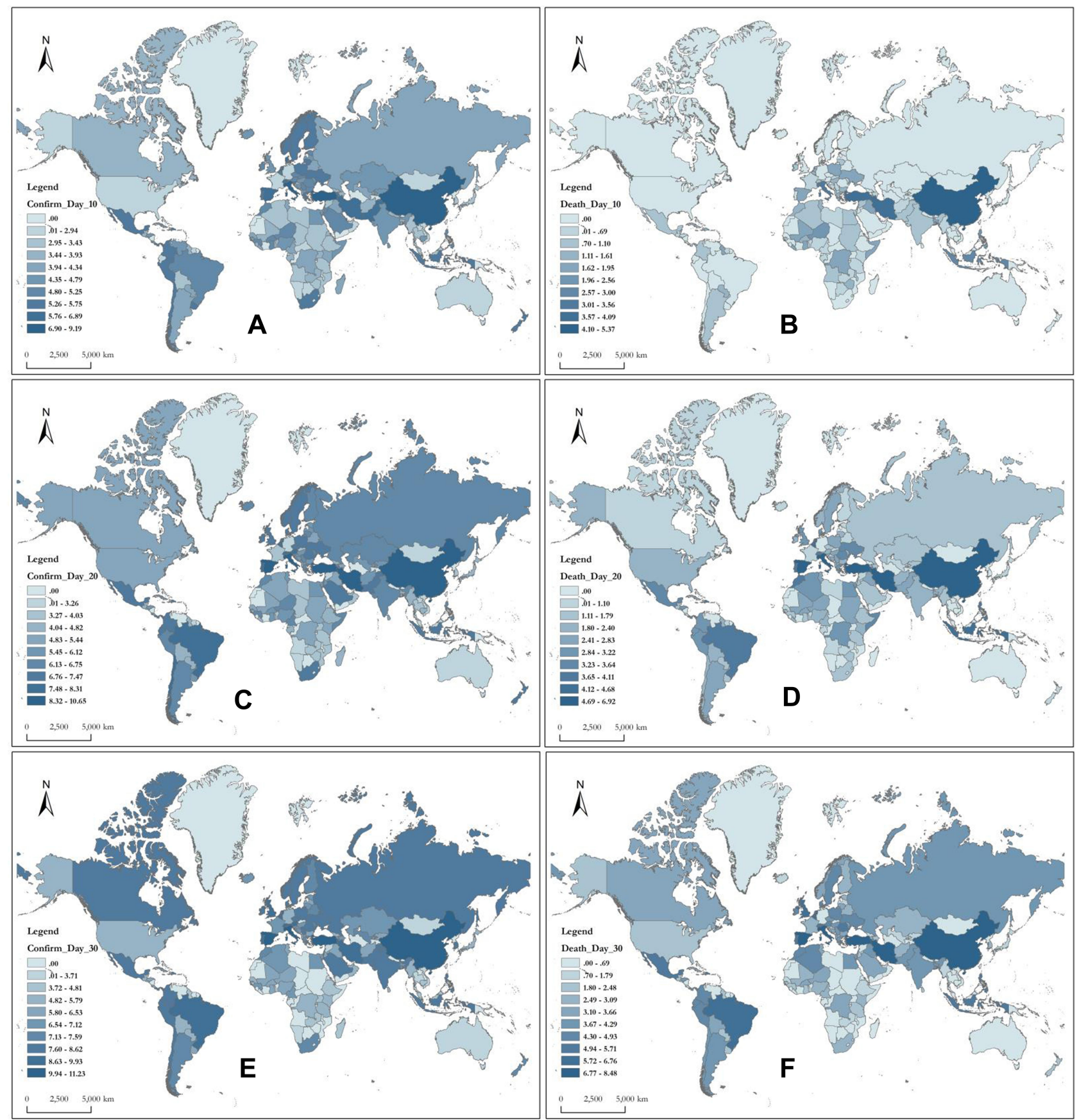

Figure 2 Spatial distribution of confirmed cases and deaths around the world: confirmed cases of day-10 (A), day-20 (C), and day-30 (E); deaths of day-10 (B), day-20 (D), and day-30 (F).

state or local course, a national association for professionals in infection control course, and certification in infection control) thus needs to be provided to nursing-home staff. It is also necessary to schedule training on a regular basis and adopt a variety of training methods (such as face-to-face training, inservices, posting flyers in care units, and computer- or videobased training tools) to improve training quality.
Asymptomatic COVID-19 residents and staff members contribute substantially to the dissemination of COVID-19 infection in long-term care facilities. ${ }^{55}$ Some approaches advocated by other researchers to protect older adults in long-term care facilities should be adopted by both developed and developing countries. Specifically, widespread testing of residents and staff members is needed, 

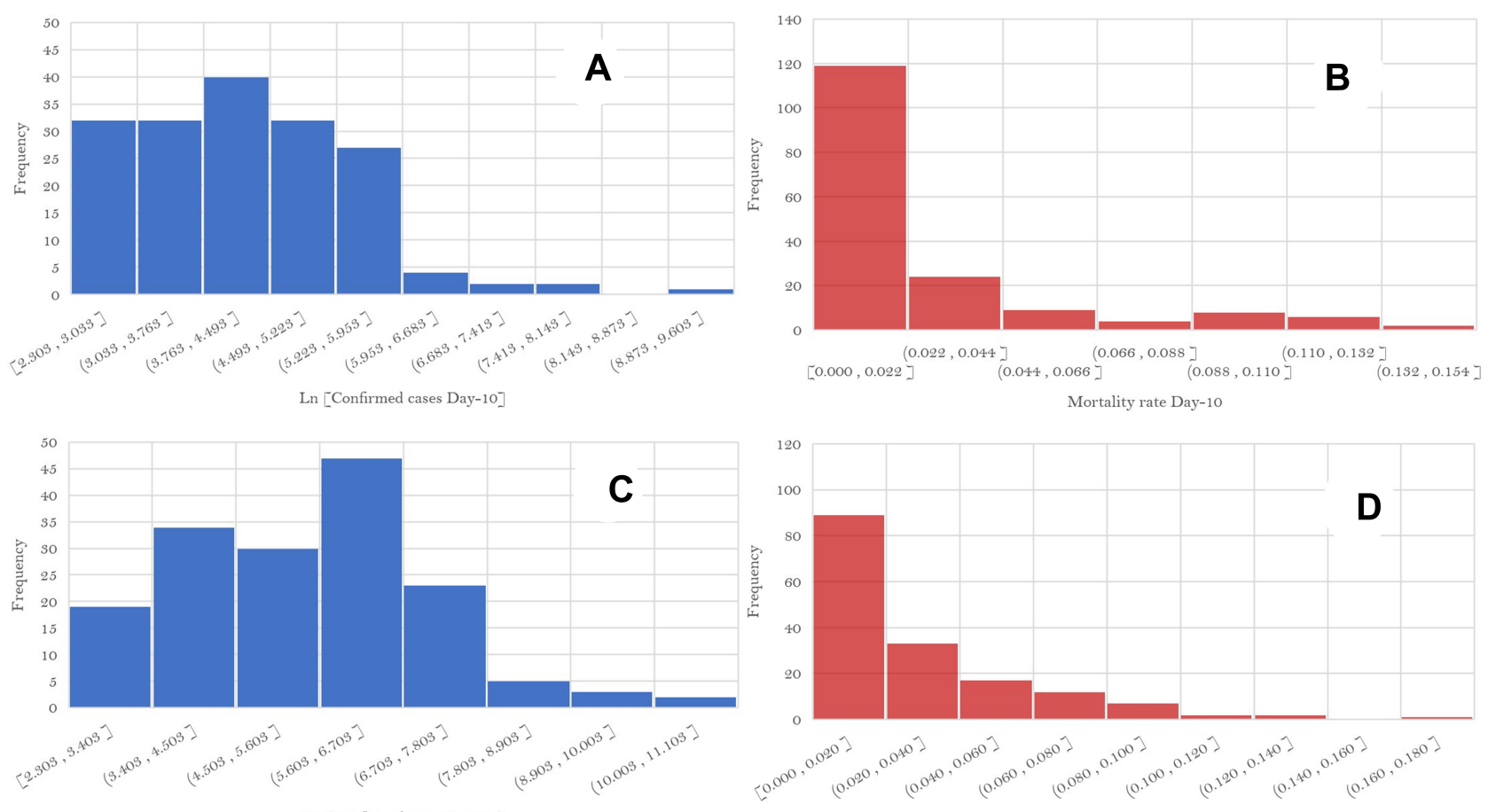

Ln [Confirmed cases Day-20]

Mortality rate Day-20
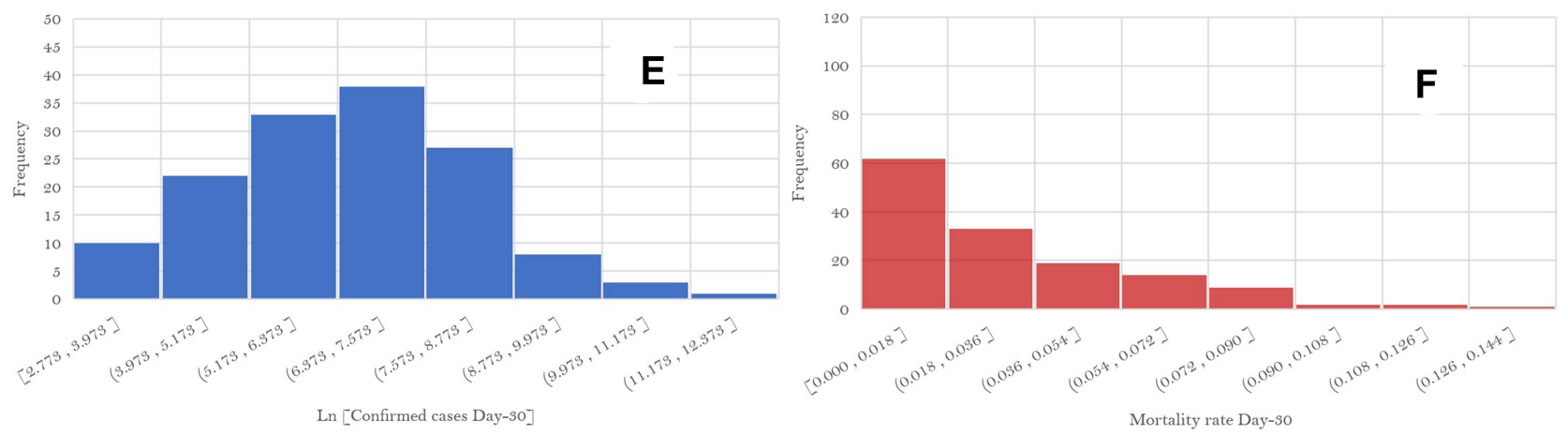

Figure 3 Confirmed cases and deaths around the world: confirmed cases of day-10 (A), day-20 (C), and day-30 (E); deaths of day-10 (B), day-20 (D), and day-30 (F),

regardless of symptom status, for close symptom monitoring. ${ }^{55,56}$ Frequent training in the use of personal protective equipment and ensuring a stockpile of appropriate personal protective equipment available on site are also recommended to prevent the spread of the current virus through contact and droplet transmission among residents and staff. $^{56,57}$ Staff compartmentalization in patients and health care-professional areas also need to be implemented in nursing homes to cut off potential infection sources. ${ }^{58}$ Current workforce practices can be further improved in several aspects, such as insistence on not attending work while unwell and paid sick leave when in quarantine, including casual or temporary staff members, and completion of staff registration in all facilities at which they work. ${ }^{56}$
Improving Medical Resource Supply Before It Is Too Late in Developing Areas is Critical for Reduction in Mortality

The findings of this study show that higher death rates are more likely to emerge in nations at the lower development level, and thus it is essential for health institutions in developing countries to improve medical resource allocation. First, establishing a stable and transparent financing mechanism can be the basis of realizing this goal. ${ }^{59}$ Second, it would help to develop an effective plan for medical resource allocation to implement risk analysis and risk management by monitoring and evaluating the shortage of medical resources for health-crisis response in developing countries. Third, developing supporting infrastructure and tools or direct investment in medical 


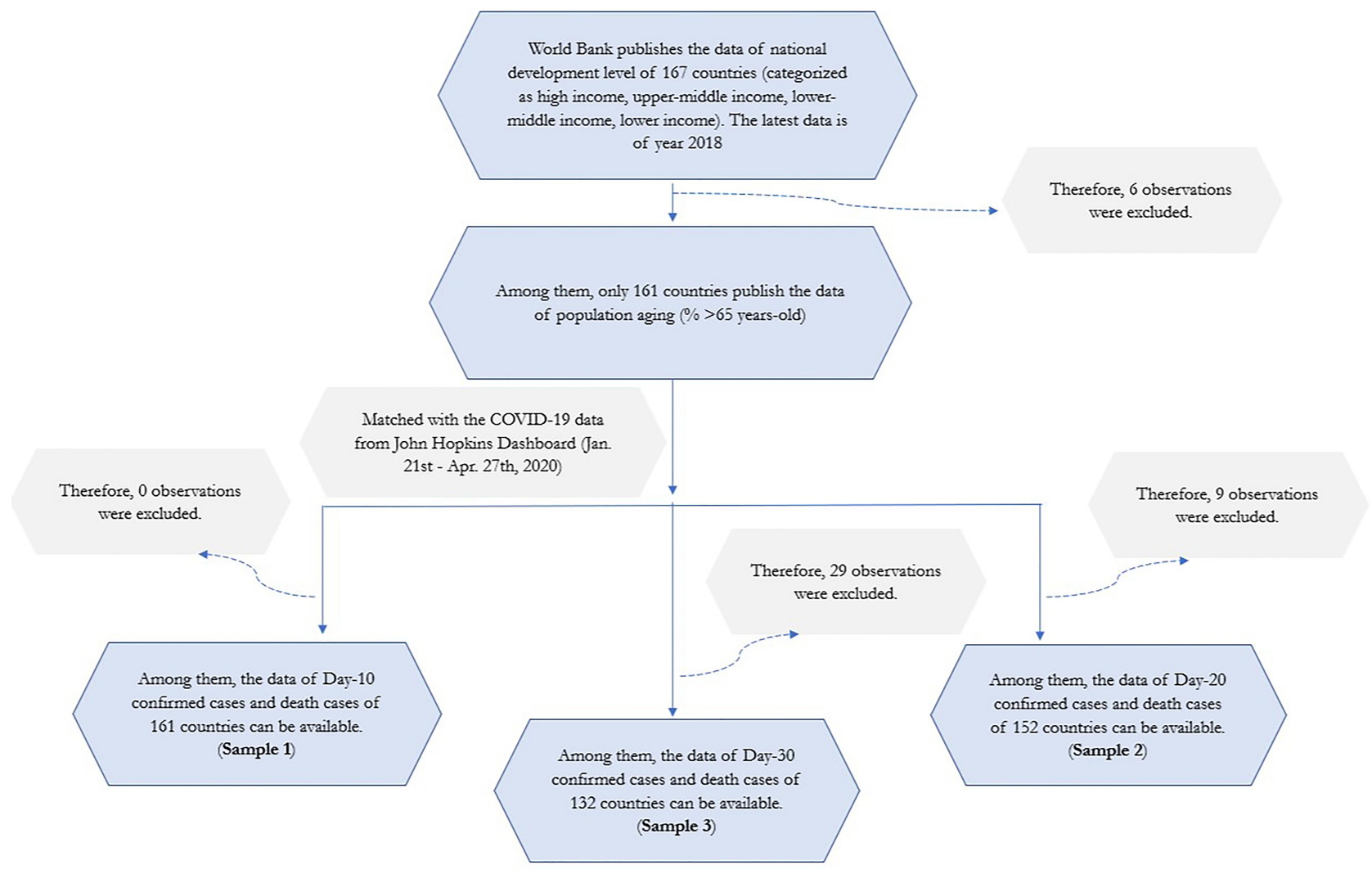

Figure 4 Flowchart of regression samples.

resources can help enhance the overall supply of medical resources in developing countries. Fourth, a multifactorial resource-allocation strategy needs considering as the primary allocation method that equally weighs in-hospital survival and comorbidities contributing to short-term mortality ( $<6$ months), ${ }^{52}$ in order to ensure that no group of people is unjustly disadvantaged by resource-allocation strategies. ${ }^{60}$

Many medications and vaccines for prevention of COVID-19 infection are currently under investigation. Medications with promising results in effectiveness against COVID-19 need considering in the lists of medical resource supplies for developing countries. ${ }^{61}$ Future COVID-19 vaccination policies implemented by developing countries need to consider aging and physical and cognitive frailty associated with aging, since dysregulation of the immune system in older adults can cause poorer responses to vaccination. ${ }^{62}$

Currently, recommended treatments for older patients with COVID-19 infection include symptomatic comprehensive supportive therapies, such as oxygen therapy, expectorants, prevention and treatment of infections, antivirals, and immunregulators. ${ }^{63}$ Early screening, early diagnosis, and close monitoring for older patients are also needed to reduce the mortality rate associated with COVID-19, considering older patients have poorer prognostic factors and are more likely to experience critical diseases. ${ }^{63}$ It is thus necessary to ensure that medical resource supply can strongly support the implementation of such treatments and examination.

\section{Susceptible Population-Specific Health- Communication and -Promotion Measures Are Needed in This Public Health Crisis}

Susceptible population-specific health-promotion practices can be promoted as effective guidance in prevention and control of this health crisis. A lesson from Tokyo can be learned regarding applying a telehealth solution, a home version of the functional training-exercise video, to help the elderly practice healthy behaviors at home. ${ }^{64}$ This breakthrough alternative to usual group-exercise activities can sustain ongoing health-promotion activities for older adults during home stays. Moreover, health communication needs to show fairness to older adults, who are the vulnerable population. ${ }^{65}$ Considering older adults suffer a decrease in cognitive processing abilities, health 
Table I Influence of population aging on confirmed novel coronavirus disease cases and deaths

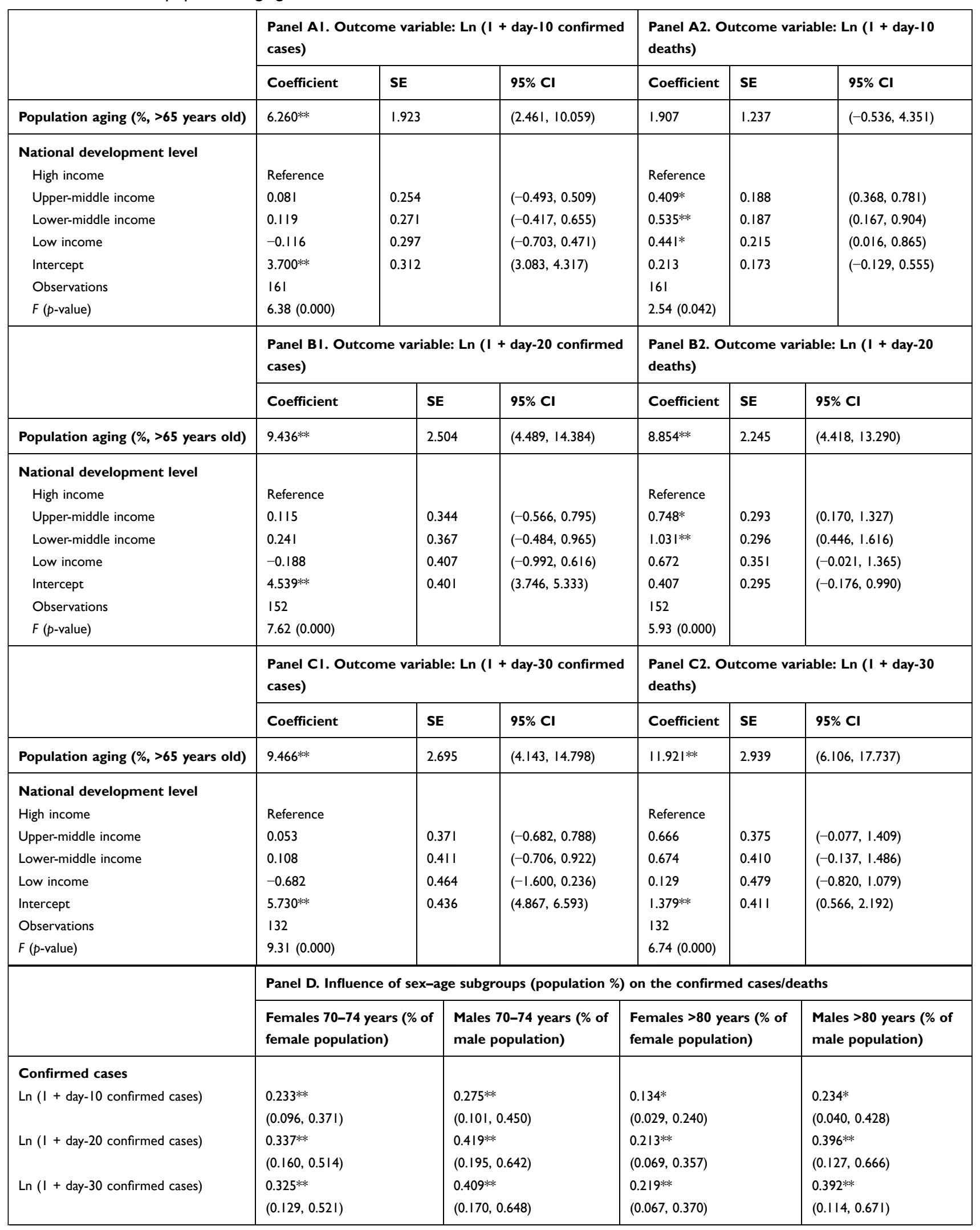


Table I (Continued).

\begin{tabular}{|c|c|c|c|c|}
\hline & \multicolumn{4}{|c|}{ Panel D. Influence of sex-age subgroups (population \%) on the confirmed cases/deaths } \\
\hline & $\begin{array}{l}\text { Females } 70-74 \text { years (\% of } \\
\text { female population) }\end{array}$ & $\begin{array}{l}\text { Males } 70-74 \text { years (\% of } \\
\text { male population) }\end{array}$ & $\begin{array}{l}\text { Females }>80 \text { years }(\% \text { of } \\
\text { female population) }\end{array}$ & $\begin{array}{l}\text { Males }>80 \text { years }(\% \text { of } \\
\text { male population) }\end{array}$ \\
\hline Deaths & & & & \\
\hline Ln ( + day-10 deaths $)$ & $\begin{array}{l}0.070 \\
(-0.014,0.154)\end{array}$ & $\begin{array}{l}0.109 * \\
(0.009,0.210)\end{array}$ & $\begin{array}{l}0.047 \\
(-0.025,0.120)\end{array}$ & $\begin{array}{l}0.117 \\
(-0.008,0.242)\end{array}$ \\
\hline $\operatorname{Ln}(1+$ day-20 deaths $)$ & $\begin{array}{l}0.322 * * \\
(0.161,0.483)\end{array}$ & $\begin{array}{l}0.448^{* *} \\
(0.250,0.646)\end{array}$ & $\begin{array}{l}0.213 * * \\
(0.075,0.352)\end{array}$ & $\begin{array}{l}0.475 * * \\
(0.242,0.708)\end{array}$ \\
\hline Ln ( + day-30 deaths $)$ & $\begin{array}{l}0.440 * * \\
(0.224,0.655)\end{array}$ & $\begin{array}{l}0.583^{* *} \\
(0.319,0.847)\end{array}$ & $\begin{array}{l}0.285 * \\
(0.107,0.464)\end{array}$ & $\begin{array}{l}0.587 * * \\
(0.266,0.907)\end{array}$ \\
\hline
\end{tabular}

Notes: For panel D, regressions were conducted to examine the influence of sex-age subgroups (population \%) on confirmed cases and deaths. Different populations (first row) were included separately as the independent variable in regressions, with country classification and intercept controlled (estimates not reported in this table to save space). For panels A-C, multivariate regression analyses were conducted. Robust regressions were conducted to control heterogeneity across countries. ${ }^{*} p<0.05$; $* *<<0.01$.

information explaining the virus, transmission, and protective measures should be clarified repeatedly and explained transparently. ${ }^{66}$ Communication formats should also be presented in an understandable way, such as with engaging animation and more attractive layouts. ${ }^{66}$ The contents of health communication need to include an emphasis on more susceptible older subgroups (eg, older males aged 70-74 years) to raise their awareness of self-prevention and control and provide reminders of the dangerous period (eg, day-20 and later for each country, based on the first day of reaching ten deaths as day-1) to guide timely prevention and control.

\section{Limitations and Future Research}

This study still has some limitations. It divided the structure of population aging into age and sex subgroups. With more information on population aging reported by countries, diversified classification can be conducted in future research to provide richer findings of relationships between population aging and the development of COVID-19. Moreover, this study adopts the classification of nation-development level of the World Bank. With an alternative official classification available, future research can examine more facets of nation-development levels for deep analysis of their association with the development of this public health crisis.

\section{Conclusion}

This study examined country-level relationships among population aging, national development level, and risk of novel coronavirus disease. Population aging was found to positively predict confirmed cases and deaths from this pandemic. Countries with a structure of population aging of a higher proportion of older males, especially those aged 70-74 years, were shown to face higher risks of confirmed cases and deaths. Compared with developed countries, developing countries were found to face higher risks of deaths from this pandemic in the short term. Targeted prevention strategies for older adults and underdeveloped areas are urgently needed.

\section{Data Sharing Statement}

The data used in this study are open-source and publicly available. The data sets were derived from sources in the public domain: the World Bank (http://datatopics.world bank.org/universal-health-coverage/coronavirus) and Johns Hopkins COVID-19 Dashboard (https://coronavirus. jhu.edu/map.html). Unrestricted reuse is permitted via an open license. More specifically, the data on national development level and population aging are published by the World Bank (http://datatopics.worldbank.org/universalhealth-coverage/coronavirus). The data set provided by World Bank is under same terms of use, unless indicated otherwise in the data or metadata. You are free to copy, distribute, adapt, display, or include the data in other products for commercial or noncommercial purposes at no cost under a Creative Commons Attribution 4.0 International License. When you download or use the data sets, you are agreeing to comply with the terms of the license. Novel coronavirus disease statistics are publicized by governments around the world and collected by the Johns Hopkins COVID-19 Dashboard (https://coronavirus.jhu. edu/map.html). The data set provided by the Johns Hopkins COVID-19 Dashboard is licensed under Creative Commons Attribution 4.0 International by Johns Hopkins University on behalf of its Center for Systems Science in Engineering. Copyright Johns Hopkins University 2020. 


\section{Ethics Statement}

This study was approved by the institutional review board of Sun Yat-sen University. As this study used publicly available data and the authors had no contact with human-related materials, no informed consent from participants was required.

\section{Consent for Publication}

Consent for publication was not required, since there are no personal identifying materials included in this manuscript.

\section{Acknowledgments}

We sincerely thank participants of seminars for providing valuable advice to improve our manuscript.

\section{Author Contributions}

All authors made a significant contribution to the work reported, whether in the conception, study design, execution, acquisition of data, analysis and interpretation, or in all these area, took part in drafting, revising, or critically reviewing the article, gave final approval tothe version to be published, have agreed on the journal to which the article has been submitted, and agree to be accountable for all aspects of the work.

\section{Funding}

We appreciate the support from the National Social Science Fund of China (20CTY017).

\section{Disclosure}

The authors of this study report no conflicts of interest for this work.

\section{References}

1. Etard JF, Vanhems P, Atlani-Duault L, Ecochard R. Potential lethal outbreak of coronavirus disease (COVID-19) among the elderly in retirement homes and long-term facilities, France, March 2020. Eurosurveillance. 2020;25(15):2000448.

2. Hubbard RE, Maier AB, Hilmer SN, Naganathan V, Etherton-Beer C, Rockwood K. Frailty in the face of COVID-19. Age Ageing. 2020;49 (4):499-500.

3. Lim WS, Liang CK, Assantachai P, et al. COVID-19 and older people in Asia: asian working group for sarcopenia calls to actions. Geriatr Gerontol Int. 2020;20(6):547-558.

4. Onder G, Rezza G, Brusaferro S. Case-fatality rate and characteristics of patients dying in relation to COVID-19 in Italy. JAMA. 2020;323 (18): $1775-1776$.

5. Comas-Herrera A, Zalakain J, Litwin C, Hsu AT, Fernandez-Plotka JL Mortality associated with COVID-19 outbreaks in care homes: early international evidence. 2020. Available from: https://tccovid.org/ 2020/04/12/mortality-associated-with-covid-19-outbreaks-in-carehomes-earlyinternational-evidence/. Accessed 15 October, 2020.

6. Niu S, Tian S, Lou J, et al. Clinical characteristics of older patients infected with COVID-19: a descriptive study. Arch Gerontol Geriatr. 2020;89:104058.
7. Kang SJ, Jung SI. Age-related morbidity and mortality among patients with COVID-19. Infect Chemother. 2020;52(2):154-164.

8. Guan WJ, Liang WH, Zhao Y, et al. Comorbidity and its impact on 1590 patients with COVID-19 in China: a nationwide analysis. Eur Respir J. 2020;55(5):2000547.

9. Bonanad C, García-Blas S, Tarazona-Santabalbina F, et al. The effect of age on mortality in patients with COVID-19: a meta-analysis with 611,583 subjects. J Am Med Directors Assoc. 2020;21(7):915-918.

10. Armocida B, Formenti B, Ussai S, Palestra F, Missoni E. The Italian health system and the COVID-19 challenge. The Lancet Public Health. 2020;5:5.

11. Smart J, Letelier A. Bridging human rights and social determinants of health: argentina, Chile, Paraguay, and Uruguay. Int J Human Rights Healthcare. 2019;13(1):3-17.

12. Ghaderi E, Hassanzadeh K, Rahmani K, et al. Prevalence of selfmedication and its associated factors: a case study of Kurdistan province. Int J Human Rights Healthcare. 2020;13(3):249-258.

13. Etemadi M, Ashtarian K, Ganji N, Kangarani HM, Gorji HA. Have the poor been considered in the Health Sector Evolution Plan? A qualitative study of the Iranian health system. Int J Human Rights Healthcare. 2019;13(1):45-57.

14. Pakdaman M, Geravandi S, Hejazi A, Salehi M, Davoodifar M. Empowering the insured under health insurance: a case study in center of Iran. Int J Human Rights Healthcare. 2019;12(5):328-338.

15. Barasa EW, Ouma PO, Okiro EA. Assessing the hospital surge capacity of the Kenyan health system in the face of the COVID-19 pandemic. PLoS One. 2020;15:7.

16. Nair PS. Population aging in sub-Saharan Africa: present and prospects. Gerontechnology. 2014;13(1):266.

17. Martinez-Alvarez M, Jarde A, Usuf E, et al. COVID-19 pandemic in west Africa. The Lancet Global Health. 2020;8:5.

18. Golaz V, Nowik L, Sajoux M. Africa, a young but ageing continent. Population Soc. 2012;491:4.

19. Jain V, Yuan JM. Predictive symptoms and comorbidities for severe COVID-19 and intensive care unit admission: a systematic review and meta-analysis. Int J Public Health. 2020;65(5):533-546.

20. Couteur DGL, Anderson RM, Newman AB. COVID-19 is a disease of older people. J Gerontol Ser a Biol Sci Med Sci. 2020;75:9.

21. Graham NSN, Junghans C, Downes R, et al. SARS-CoV-2 infection, clinical features and outcome of COVID-19 in United Kingdom nursing homes. $J$ Infect. 2020;81(3):411-419.

22. Abrams HR, Loomer L, Gandhi A, Grabowski DC. Characteristics of U.S. nursing homes with COVID-19 cases. J Am Geriatr Soc. 2020;68(8):1653-1656.

23. Lanini S, Vairo F, Puro V, et al. Higher death rates in the Italian COVID-19 outbreak: a comparative modelling analysis of 8,342 Italy and 44,672 China cases. SSRN Working Paper. 2020. Available from :https://papers.ssrn.com/sol3/papers.cfm?abstract_id=3556640. Accessed 18 October, 2020.

24. Ponticiello M, Mwanga-Amumpaire J, Tushemereirwe P, Nuwagaba G, King R, Sundararajan R. Everything is a mess: how COVID-19 is impacting engagement with HIV testing services in rural southwestern Uganda. AIDS Behav. 2020;24(11):1-4.

25. Goldstein JR, Lee RD. Demographic Perspectives on mortality of COVID-19 and other epidemics. Proc Natl Acad Sci U S A. 117 (36):22035-22041.

26. Chaubey G. Coronavirus (SARS-CoV-2) and mortality rate in India: the winning edge. Front Public Health. 2020;8:397.

27. Nicodemo C, Barzin S, Cavalli N, et al. Measuring geographical disparities in England at the time of COVID-19: results using a composite indicator of population vulnerability. BMJ Open. 2020;10(9):e039749.

28. Gebhard C, Regitz-Zagrosek V, Neuhauser HK, Morgan R, Klein SL. Impact of sex and gender on COVID-19 outcomes in Europe. Biol Sex Differ. 2020;11(1):29.

29. Jin J-M, Bai P, He W, et al. Gender differences in patients with COVID-19: focus on severity and mortality. Front Public Health. 2020;8(8):152. 
30. Guzek D, Skolmowska D, Głąbska D. Analysis of gender-dependent personal protective behaviors in a national sample: polish adolescents' COVID-19 experience (PLACE-19) study. Int J Environ Res Public Health. 2020;17(16):5770.

31. Anderson JL, Warren CA, Perez E, et al. Gender and ethnic differences in hand hygiene practices among college students. Am J Infect Control. 2008;36(5):361-368.

32. Mariwah S, Hampshire K, Kasim A. The impact of gender and physical environment on the handwashing behaviour of university students in Ghana. Trop Med International Health. 2012;17(4):447-454.

33. Alshammary F, Siddiqui AA, Amin J, et al. Prevention knowledge and its practice towards COVID-19 among general population of Saudi Arabia: a gender-based perspective. Curr Pharm Des. 2020;26.

34. Yang J, Zheng Y, Gou X, et al. Prevalence of comorbidities in the novel Wuhan coronavirus (COVID-19) infection: a systematic review and meta-analysis. Int J Infect Dis. 2020;94:91-95.

35. Gambaryan MG, Drapkina OM. Tobacco smoking and COVID-19: an old enemy in a new guise. Review of current publications. Cardiovasc Ther Prev. 2020;19(3):2604.

36. Sorensen G, Gupta PC, Pednekar MS. Social disparities in tobacco use in Mumbai, India: the roles of occupation, education, and gender. Am J Public Health. 2005;95(6):1003-1008.

37. Neufeld KJ, Peters DH, Rani M, Bonu S, Brooner RK. Regular use of alcohol and tobacco in India and its association with age, gender, and poverty. Drug Alcohol Depend. 2005;77(3):283-291.

38. Li J, Yuan B, Zeng G. The attitude towards e-cigarettes, disengagement belief, e-cigarette health literacy and susceptibility among youths and adolescents. Int $J$ Adolesc Youth. 2020;25(1):849-860.

39. Dwivedi R, Pradhan J. Revisiting equity in healthcare spending through capability-approach: assessing the effectiveness of healthinsurance schemes in reducing OOPE and CHE in India. Int $J$ Human Rights Healthcare. 2020.

40. Stein F, Perry M, Banda G, Woolhouse M, Mutapi F. Oxygen provision to fight COVID-19 in sub-Saharan Africa. BMJ Global Health. 2020;5(6):e002786.

41. Yuan B, Wang Z, Li J. Social vulnerability and infant mortality in space dimension: an investigation of the world's most underdeveloped West Africa coastal area. Int J Human Rights Healthcare. 2020;13(3):239-248.

42. Barua P, Narattharaksa KC. The health status and insurance affiliation of stateless children in Tak Province, Thailand. Int J Human Rights Healthcare. 2020.

43. Da Luz Scherf E, Viana da Silva MV, Fachini JS. The management (or lack thereof) of COVID-19 in Brazil: implications for human rights and public health. Int J Human Rights Healthcare. 2020.

44. Chaudhry K, Prabhakar AK, Prabhakaran PS, Prasad A, Singh K, Singh A Prevalence of tobacco use in Karnataka and Uttar Pradesh in India. Final report of the study by the Indian Council of Medical Research and the WHO South-East Asian Regional Office, New Delhi; 2001.

45. Li J, Yuan B, Zeng G. Campus policy on tobacco prohibition and tobacco use among youth in sub-Saharan Africa: an investigation based on the perspectives of school personnel. Risk Manag Healthc Policy. 2020(13):1939-1950.

46. Jain VK, Iyengar K, Vaish A, Vaishya R. Differential mortality in COVID-19 patients from India and western countries. Diabetes and Metabolic Syndrome. Clin Re Rev. 2020;14(5):1037-1041.

47. Kumar P, Chander B, Prasad R. COVID-19 mortality: probable role of microbiome to explain disparity. Med Hypotheses. 2020;144:110209.

48. Diop BZ, Ngom M, Biyong CP, Biyong JNP. The relatively young and rural population may limit the spread and severity of COVID-19 in Africa: a modelling study. BMJ Global Health. 2020;5:5.
49. Cowper B, Jassat W, Pretorius P, et al. COVID-19 in long-term care facilities in South Africa: no time for complacency. South Afr Med J. 2020;110(10):962-963.

50. Fisman DN, Bogoch I, Lapointe-Shaw L, McCready J, Tuite AR. Risk factors associated with mortality among residents with coronavirus disease 2019 (COVID-19) in long-term care facilities in Ontario, Canada. JAMA Net Open. 2020;3:7.

51. Lau JTF, Yang X, Tsui H, Kim JH. Monitoring community responses to the SARS epidemic in Hong Kong: from day 10 to day $62 . J$ Epidemiol Community Health. 2003;57(11):864-870.

52. Farrell TW, Ferrante LE, Brown T, et al. AGS position statement: resource allocation strategies and age-related considerations in the COVID-19 era and beyond. J Am Geriatric Soc. 2020;68 (6):1136-1142.

53. Patanavanich R, Glantz SA. Smoking Is Associated with COVID-19 progression: a meta-analysis. Nicotine Tobacco Res. 2020;22 (9):1653-1656.

54. Herzig CTA, Stone PW, Castle N, Pogorzelska-Maziarz M, Larson EL, Dick AW. Infection prevention and control programs in US nursing homes: results of a national survey. $\mathrm{J} \mathrm{Am} \mathrm{Med} \mathrm{Dir} \mathrm{Assoc.}$ 2016;17(1):85-88.

55. Blain H, Rolland Y, Schols JMGA, et al. interim EuGMS guidance to prepare European long-term care facilities for COVID-19. Eur Geriatr Med. 2020;2020(3):1-15.

56. Crotty F, Watson R, Lim WK. Nursing homes: the titanic of cruise ships - will residential aged care facilities survive the COVID-19 pandemic? Intern Med J. 2020;50(9):1033-1036.

57. Rios P, Radhakrishnan A, Williams C, et al. Preventing the transmission of COVID-19 and other coronaviruses in older adults aged 60 years and above living in long-term care: a rapid review. Syst Rev. 2020;9(1):218.

58. Rolland Y, Lacoste MH, De Mauleon A, et al. Guidance for the prevention of the COVID-19 epidemic in long-term care facilities: a shorts-term prospective study. $J$ Nutr Health Aging. 2020;24:812-816.

59. Tabari-Khomeiran R, Ehsani-Chimeh E, Kiakalayeh AD, Rad EH, Delavari S. Inequity in the distribution of rural family physicians in Iran: A cross sectional study. Int $J$ Human Rights Healthcare. 2019;12(4):258-266.

60. Farrell TW, Francis L, Lundebjerg NE. The later Innings of life: implications of COVID-19 resource allocation strategies for older adults. J Am Geriatric Soc. 2020;68(12):2714-2715.

61. Shahid Z, Kalayanamitra R, McClafferty B, et al. COVID-19 and older adults: what we know. J Am Geriatric Soc. 2020;68:926-929.

62. Palermo S. Covid-19 pandemic: maximizing future vaccination treatments considering aging and frailty. Front Med. 2020;7:558835.

63. Chen T, Dai Z, Mo P, et al. Clinical characteristics and outcomes of older patients with coronavirus disease 2019 (COVID-19) in Wuhan, China: a single-centered, retrospective study. J Gerontol Ser a Biol Sci Med Sci. 2020;75(9):1788-1795.

64. Aung MN, Yuasa M, Koyanagi Y, et al. Sustainable health promotion for the seniors during COVID-19 outbreak: A lesson from Tokyo. $J$ Infect Develop Countries. 2020;14(4):328-331.

65. Altshuler E. Coronavirus containment depends on human rights: freedom of expression and press are needed to fight pandemic. Int $J$ Human Rights Healthcare. 2020.

66. Van den Broucke S. Why health promotion matters to the COVID-19 pandemic, and vice versa. Health Promot Int. 2020;35(2):181-186. 


\section{Publish your work in this journal}

Risk Management and Healthcare Policy is an international, peerreviewed, open access journal focusing on all aspects of public health, policy, and preventative measures to promote good health and improve morbidity and mortality in the population. The journal welcomes submitted papers covering original research, basic science, clinical \& epidemiological studies, reviews and evaluations, guidelines, expert opinion and commentary, case reports and extended reports. The manuscript management system is completely online and includes a very quick and fair peer-review system, which is all easy to use. Visit http://www.dovepress.com/testimonials.php to read real quotes from published authors. 